\title{
Commentary
}

\section{Perspectives on COVID-19}

\author{
Arthur Dunkley \\ Consultant Surgeon, Taunton, UK \\ E-mail: arthurdunkley75@gmail.com
}

Received 4 September 2020

Accepted 20 September 2020

\begin{abstract}
A few ideas that deserve to see the light of day. I wrote this essay on 23/3/2020. I have started updating in the form of post scripts. Please relate the information to the date on which it was written.
\end{abstract}

Keywords: COVID-19, virus, lockdown, humans, planet earth, commentary

\section{$23 / 3 / 2020$}

We humans, a sentient species of significant (we think) capabilities, are at the moment engaged in combat with a pathogenic virus - a tiny self-replicating blob of nucleic acid and protein (stolen from its host - us) with no intelligence at all. The virus, called COVID-19, does have a powerful capability for replication and transfer and, like other replicating (living or near living) species, the power to adjust or 'evolve' against the stresses applied to it from its host environment.

We are informed that we are locked in a deadly war and the virus is killing approximately 1 in 10 humans and has brought the processes of human function to its economic knees. We (clever people) on the other hand, isolate ourselves and our society and give up our economic stability while we wait for it to go away!

No social contact, no travel, panic buying with no loo rolls, no factories working, no normal health services and a sense of disaster and helplessness among our leaders leading to panic decisions and monumentally foolish directives which are impacting seriously on the mental health and behaviour of each human individual - no pubs for example!!

And we humans have declared that we are at war with this replicating chemical structure.

What on earth are we thinking.

This is a virus - it does not think or feel. It is basically a replicating chemical with one major ability it will try to survive in any environment it is specialised for by its evolutionary history. It is incapable of going to war.

Or is it? 
Its environment is us! Perhaps it could go to war indirectly by changing us.

Yes - it seems possible. It may have already succeeded!

We have already changed - we have isolated ourselves to make viral transfer more difficult.

The virus now has no other adaptive evolutionary options but to improve its transmissibility and its virulence in order to survive. Viruses replicate very efficiently and very, very frequently, at a rate inversely proportional to their size and complexity. This means that humans take on a positively paralysing slowness of replication by evolutionary comparison. Humans make a new generation once every 20 to 25 years, while viruses replicate in minutes. This means that evolution for macro-species (such as humans) is very slow, while evolution for micro-species (such as bacteria and viruses) is, by comparison, blindingly rapid. Small changes in virulence and transmissibility which occur with each generation of viruses and improve transmissibility (against a clumsy attempt to make it more difficult - 'lockdown' by human governments for example) will survive to dominate within the virus population as the evolutionary process kicks in. Soon we will have a COVID-19 which is much more efficient at transmission between hosts.

It may also be able to improve its replicative potential by affecting the host for longer periods and more symptomatically. An increase in its virulence and the length of time it remained infective (transmissible) would aid its spread and survival in this behaviourally changed human environment. It would have the potential to become a lethal pandemic.

'Lockdown' our leaders cry - 'isolate yourselves' and we can starve the virus of opportunities. This could have the effect of reducing the numbers of new infections - but the world's economy can't survive in permanent lockdown.

Economies would die and people would then die in billions.

Lockdown!

Rubbish - what are our addled leaders thinking. You cannot lockdown 8 (plus) billion people in any case - these are human beings! Look at their history - prison breaks are a universal part of our penal systems! There will be civil commotion and it will become violent. We are, during lockdown, under imposed statutory house arrest without having committed any crime whatsoever. Nevertheless completely innocent people are now being arrested and fined or sometimes imprisoned, for breaking the rules of 'lockdown', laid down by dictatorial government statutes against entire national populations all over the planet. What did they think would happen under these circumstances?

And what about those people who have to move around to provide essential services? Doctors, nurses, plumbers, refuse collectors and people providing food. 'Ah' say our ignorant leaders, they will have to wash or chemically sterilise their hands.

This is a pipe dream - a 'hope springs eternal' form of wishful thinking. The virus will adapt and evolve to circumvent the new stress on their home turf. That is what they are doing all the time! They have been working on it for a couple of billion years - they are very good at it! They are already well able to produce variant forms with pandemic potential every few years and have been happily doing so in our magnified and urbanised populations for centuries. Overpopulation is a culture medium for easily transmitted pathogens and already $60 \%$ of humans live in or near cities and both population and urbanisation are growing rapidly.

COVID-19 panic means we are heading for a global 'lockdown'. This time we do have something different from what has happened before!

We are creating the very global environment in which COVID-19 can evolve from a dangerous but straightforward pathogen to a superbug of catastrophic capabilities - the whole world has become a super culture medium for breeding a potentially deadly organism. The virus has already become a superbug and may now unleash a new kind of war on us - and we will have created it ourselves! 
We will have created our own superbug for the entire planet - and no amount of international agreements about the use of biological weapons will make any difference whatsoever.

After all, viruses are not usually signatories to agreements.

Let us hope that we can quickly find a new drug with which to treat COVID-19 or a way to immunise the 8 (plus) billion people on the planet soon - a difficult task made more difficult by our rapidly devolving, soon to be stationary economy.

There can be little doubt that the damage to our economic productivity will be gargantuan (in the realm of multi-trillions of dollars) and we will not recover for many years, if ever. Poverty and stress will escalate their impact and deaths due to other, non-viral related factors, will skyrocket - ultimately killing more people than the virus ever could.

And what if we don't find an immunisation capability?

Is there an alternative way we could have tried, or could maybe still try, to deal with this in the future? The thinking here may be logical but will be very difficult for most people to accept.

If humanity chose globally to do nothing about aggressive isolation techniques and continued to function normally many people would get COVID-19 and approximately one twentieth would die.

Actually that figure is biased by inadequate numbers on the real rate of infection and survival - it would be more like 1 in 100 or 1 in 200 deaths among newly infected individuals - and most of those would have pre-existing high risk factors in their history.

However if we used the trillions of dollars of resources that lockdown is now costing us, to build and extend medical facilities for research and treatment, many more would be saved - and the facilities would remain for future use. Present population density virtually guarantees future pandemics and the facilities will be put to good use. The jobs made available by the creation of these new facilities may also help save the expenditure of the multi-trillions that will be needed if we can ever revive the global economy. If medical services fail because we chucked our economy, millions more of those affected by the virus will be headed for the happy hunting grounds. Existing global medical infrastructure is already incapable of dealing with the rapidity and numbers of COVID-19 patients that are appearing on their doorstep, particularly in developing nations.

One other point of logic is that the world's population would, for the first time in recent history (since the last world war) be reduced toward coming in line with Earth's resources. COVID-19 reinfections would become sparse and would maybe die out as suitable susceptible individuals diminished. As more people that have been infected become resistant or immune, the parasitic virus would be deprived of its replicating resource (us) and would then be drastically reduced or die out. It is called 'herd immunity' and has happened before with pandemic pathogens. That would leave nine-tenths (more likely nine and nine tenths) of the world's population intact and a functioning economy with few long term hardships.

\section{$26 / 3 / 2020$}

Lockdown has already occurred - it is now a daily fact of life, everybody is involved in some way and it should, in time, mean that cross infection in the community slows down.

Perhaps we could combine the concepts of isolation and normality and have them running simultaneously! People from young children to the age of 65 (perhaps) should be free to live normally but with simple safeguards (eg, the use of face masks in public).

The pathogenicity for children seems to be much lower than for adults. This means that loss of education potential could be reduced by more schools with more space for distancing and more computers to 
encourage learning on the World Wide Web. Hospitals for improving the outcomes of isolation and treatment of sick individuals would also help. This would maintain and improve services and also provide jobs with income and a strong economy.

Such balanced and carefully considered steps would probably cost much less than the multi-trillions it will cost in damaging the global economy by simple lockdown.

People who are elderly or medically predisposed, could be assisted in isolation and shielding practices to reduce their risk of contracting the virus and thus reduce medical costs to the society at large. The money saved by having a functioning economy could assist this kind of exercise - but how would we logistically achieve it in the world's poor and population overloaded, high density, plastic favelas (shanty towns). The logistical issues alone are mind boggling but not impossible - in China they built a new hospital in ten days!

The possibility of chaotic resurgence of human interaction may overtake us anyway, as we find our own way to adapt. Eight (plus) billion human beings is simply too many to hold in permanent lockdown. We are not known, as a species, for our ability to function globally. Pretty soon there will be variations of opinion or an argument about resources, national borders or religion - or some other catalyst which will precipitate non global thinking and behaviour.

Our present world leaders (Trump, Putin, Johnson and many others in the Middle and Far East and South America) do not fill me with confidence about their ability to resist retaliation with nuclear resources.

There will then be (probably) a real war which will destabilise and damage human populations even more quickly and kill even more people than COVID-19 could have dreamed of!

\section{$30 / 3 / 2020$}

There is an escalation of cases and deaths in epidemic proportions across the first world despite shutdowns. These will escalate over the next few days or weeks.

\section{$1 / 3 / 2020$}

In India poor people in the cities are leaving in hundreds of thousands as they fear starvation and wish to return to their villages. There is civil and political unrest. Elsewhere parties have occurred in the street!

People are now being put in Gaol if they leave their homes. What about human rights? Lockdown is house arrest on a national basis.

Medical services are finding it difficult to cope in many places where economies are already collapsing.

Large numbers of major industries that sustain our economies are filing for administration or simply closing down.

\section{$5 / 4 / 2020$}

Today's statistics indicate over 1.2 million cases of confirmed COVID-19 infection and almost 65000 deaths worldwide. I.e. approximately $5 \%$. However we do not know the true number of people who have had coronavirus infections as they have not been tested. The majority of people tested are those who have symptoms - the total for infected persons not tested are likely to be two or three times higher than present figures indicate and this suggests mortality will be much lower than 5\%. Population testing has now begun and we may have more solid statistics soon. 


\section{$17 / 4 / 2020$}

Today's statistics indicate that almost 2.3 million people have tested positive for coronavirus and 150,000 have died. This gives a mortality rate of just shy of $7 \%$. This is completely useless as a statistic as despite testing we have NO real idea of the number of infected cases as we haven't tested every person yet. Every person on the planet who has already had this illness and survived but remained undiagnosed, or has it at present but has not died or been tested would reduce this mortality statistic - there must be millions by now.

Yesterday it was reported that reinfections with COVID-19 had been diagnosed. This means that either: (a) Natural immunity does not occur - highly unlikely.

(b) That the protein encasing the pathogenic nuclear material (in this case RNA) is protecting itself by generating a new or different protein sheath. It is the protein shell of the virus that excites the human immune system to build immunity. Reinfections suggest it is already evolving out of our control. This is not unexpected - we have known (for many years) that "flu" viruses can change their immune signature and pathogenicity.

or (c) Our testing is rubbish.

The majority of countries have extended or are planning to extend, their national lockdowns. The longer this persists the greater the difficulty of recovering the disastrous economic decline associated with it. Associated with this, the longer people are corralled (imprisoned) in their homes the greater the risk of escalating civil unrest - a phenomenon already being seen in many parts of the world. We have not yet even considered the long term health effects due to both physical deprivations and mental stress that are already beginning to occur and will get worse.

\section{$18 / 4 / 2020$}

Today's news indicates a turn-around in thinking which seems to be just beginning - America, some European countries and Far East countries are considering the reversal of lockdown policies.

Civil and military unrest amounting to war has broken out in Myanmar. This appears once more to be related to the Rohingya crisis rather than COVID-19, but any war situation with uncontrolled movement of people, is a first class mechanism for promoting virus spread.

China has just released new figures for COVID-19 infections and deaths for the Wuhan city area where the virus is thought to have originated. They are $50 \%$ higher than figures previously quoted for this area. "New" statistics and time references for COVID-19 in China will critically impact on very recent trade agreements with China which specifically absolve the Chinese of responsibility for meeting payments in the event of global pandemic conditions.

The implications are obvious. China seems to have a peculiar penchant for telling fibs to suit its own Political or Economic practices.

\section{$1 / 6 / 2020$}

I have not returned to this subject for over six weeks and have been asked by a few folks to provide a 'progress report' on the pandemic outcomes. Most of the issues foreseen have happened already and don't require discussion - the obvious one is the catastrophic collapse of the macro economy and more than the expected number of small businesses closed as a direct result of 'shutdown' 
One of the things that I did not fully foresee (and should have) was the 'fear factor' generated by the persistent quoting of infection and 'death' statistics constantly paraded by the media. As a result many people have persisted with the sense that 'if you contract a COVID-19 infection you die'. Despite some voices of reason appearing out of the globally disorganised responses to the pandemic, many administrative decisions have been 'panic-induced' by various leaders and nations.

None of these early statistics were accurate because the vast majority of people infected with COVID19 would have minor symptoms or be asymptomatic altogether and therefore would not present for testing at all and would be 'lost' from the statistical analysis of 'global' cases. This would be particularly problematical for poorly resourced nations and the numbers would be in the order of several millions.

Despite this criticism the pandemic is a serious problem and has now lasted long enough to give some real statistical trends. The COVID-19 statistics quoted in the news for today state that the global number of infected cases exceeds 10 million and the number of deaths is around half a million. This gives an associated mortality rate of $5 \%$.

The majority of these 5\% would have associated pathology with a high risk of dying by getting a simple Flu or a severe 'cold' which everybody gets from time to time. This would also include those having a long standing associated previous disease or weakness dying of 'natural' causes. This would reduce the numbers for specifically COVID-19-caused deaths by a very large number - let us estimate (quite reasonably) half of the total number published for today - 250,000.

We could also comfortably add half again to the known (tested) number of global infections arising from those people not tested because of subclinical infections and therefor excluded from the published statistic. This means the total number of COVID-19 infections globally could be reasonably assessed at 15 million.

This would make global mortality DIRECTLY related to COVID-19 infections as a quarter of a million. The mortality statistic now becomes $1.6 \%$.

In the next few months the statistics will vary widely between countries because the virus arrived on widely differing dates and circumstances, which would alter the point at which you take measurements relative to the course of the pandemic. Ultimately they will stabilise with built in local variations due to differences in climate, population density, population age averages, national medical resources, etc. Personally I think there will be between one and two percent mortality overall. In fact it seems to be a worldwide political habit.

\section{Proper perspective}

There is no doubt that this pandemic represents a humanitarian and economic disaster and it will not disappear soon. It is also a global phenomenon due to modern free movement of people and a high percentage of asymptomatic infections. This is tempting many people into a fear of Armageddon. We need to try and find a 'common sense' balance of the COVID-19 potential for destruction by comparison with what has happened during and after the catastrophic disasters of the past.

A short time ago I was sent a short article found on the internet by a very good friend who is also now retired but has a great interest in what is going on in the world. My friend is not the author and I do not know who the writer of this piece may be - but many thanks to him/her.

I think it is an excellent way of illustrating the perspectives of the COVID-19 epidemic rather than simply providing a long list of comparative numbers. I have checked the statistics for their accuracy and have added a couple of sentences to make things clearer. 
It is called

\section{'Born in 1900'.}

"For a small amount of perspective (on the COVID-19 pandemic) at the moment, imagine you were born in 1900 (one hundred and twenty years ago).

When you were 14 years old World War l began. It ended on your 18th birthday and 22 million people were killed.

Later in the same year the Spanish Flu epidemic hits the planet and runs until you are 20. Actual flu deaths are unknown but estimated at 50 million people in those two years.

When you are 29 years the Great Depression begins. Unemployment hits 25\%, global GDP drops 27\%. That runs until you are 33. The US way of life nearly collapses along with the global economy. Millions die of starvation.

When you turn 39, World War ll starts and in 1941 America joins this war. Between your 39th and 45th birthdays 75 million people perish in the war and a further 6 million Jews and 7 to 10 million other groups (Soviet, Polish, Romanian and other civilian European noncombatants) are slaughtered in the Holocaust.

When you are 52 the Korean War starts and 5 million people perish. Probably as many as 5 million more die of starvation after the war ends, especially in North Korea. Douglas Mac Arthur described it in horrifying terms and estimated civilian deaths alone at around 20 million.

When you are approaching 62 years of age the Cuban missile crisis, a tipping point in the Cold War, brought the planet close to nuclear devastation. Life on earth as we know it, could have ended.

At 64 the Vietnam War begins and doesn't end for many years. At least 4 million people die in that conflict.

As you turn 75 the Vietnam War finally ended but millions died of starvation especially in North Vietnam. In Cambodia Khmer Rouge genocide kills up to two million people.

There have been many wars since then with millions of lives lost - the Balkan wars, Iran, Iraq, Ukraine, Libya, Syria and many more. In Africa the many political and ethnic genocides have accounted for over 10 million deaths in the last fifty years.

Our Great Grandparents, Grandparents and parents survived all these disasters.

Let us keep things in perspective. We can get through this".

The global population in 1900 was around 1.6 billion people. By 1950 it had grown to around 2.5 billion and took until 1970 to reach 4 billion. By the time we reached the year 2000 the world population had reached 6 billion and in 2020 it will probably reach 8 billion. This is an increase of 6 billion $(6,000,000,000)$ human beings in 120 years - an exponential population increase. This happened despite the attrition of the numbers of dead quoted in the article above.

Although the growth rate has slowed a little in the last two years, dropping from $1.1 \%$ to $1.05 \%$, this huge number of humans, together with this kind of population growth, will soon overwhelm the space and habitat requirements needed to maintain a balanced environment on Planet Earth.

We can go on producing enough food to maintain the expanding population for a long while to come, but doing so would be acting to contribute, over time, to the failure of the long term capacity of our planet to support us.

There is very little doubt that we can survive the COVID-19 disaster without undue damage to the total population and the overall future economy if we adopt a guarded hands off policy and co-operation among Nations. 
What is in doubt is the human animal's ability to shift thinking and behaviour characteristics from the present embedded directions. We have accepted as normal the blind technological expansion and resulting development because it aims toward the achievement of greater wealth and privilege. Expansion and development have become almost a religious mania. But they will eat up the planetary spaces and resources until they achieve the position of responsibility for global destruction.

The human race needs to become expert in a new field - ecological balance. With exponential growth of populations all wanting space and food as well as 'modern' life privileges, such as power, travel, comfortable homes, accessible healthcare, easy communication and endless 'things' available to satisfy consumer needs, we will not survive. Without significant changes in population dynamics and resource usage we are probably doomed to extinction. We already exist on a planet where pre-existing arguments about 'rights' to our most critical life necessities are going to escalate to war - those components are air and water- and we are already on the cusp. Wars will occur within the next generation. In a few places they have started already.

Wake up leaders of Planet Earth. We are facing a threat of extinction far more threatening than COVID19 - and you are bickering amongst yourselves, trading insults and thereby attempting to garnish your reputations as 'caring' about your people and your planet, currying favour with voters to sustain reelection.

Wake up humankind - all 8 billion of you! You are at this very moment moving toward destroying your own species on your own home planet. Planet Earth is at present the only one you have. It is home. What kind of blind idiot creature destroys his only home. 


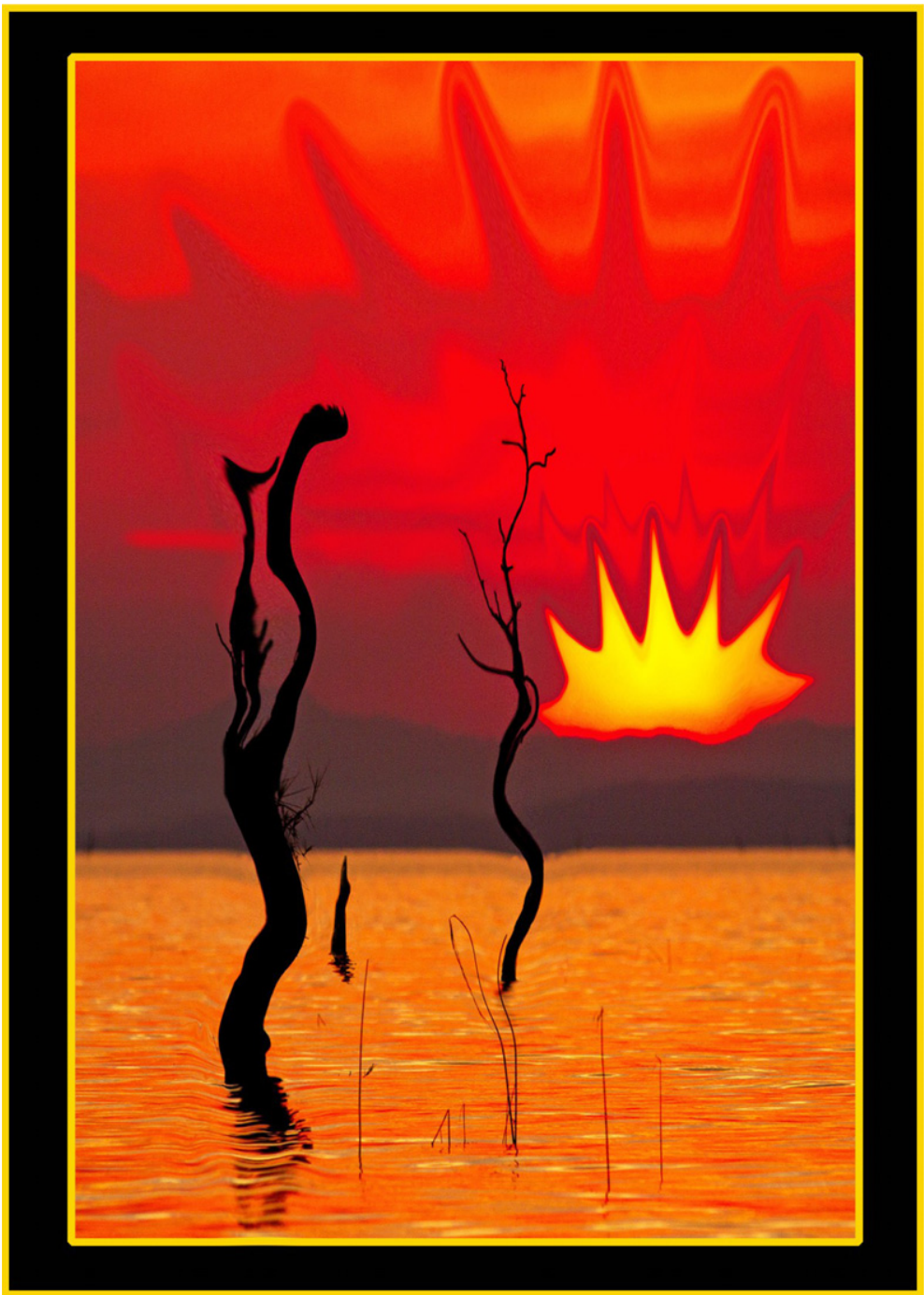

Fig. 1. Gaunt sunrise (author's own work). Surreal artwork adapted from an actual photograph. A fierce, empty planet with the elements over which we will go to war. 